\title{
VALIDATED LIQUID CHROMATOGRAPHY/TANDEM MASS SPECTROMETRY METHOD FOR DETERMINATION AND PHARMACOKINETIC STUDY OF METOLAZONE IN RAT PLASMA
}

\author{
Ramkumar Dubey, Soumyajit Das, Kamal Kant and Manik Ghosh* \\ Department of Pharmaceutical Sciences and Technology, Birla Institute of Technology, \\ Mesra, Ranchi, Jharkhand (835215), INDIA \\ *Corresponding Author's E-mail: manik@bitmesra.ac.in \\ Tel.: +916512276247; Fax: +916512275290
}

\begin{abstract}
A simple, highly sensitive and rapid LC-MS/MS method has been developed and validated for the quantification of metolazone in rat plasma using irbesartan as internal standard (IS). After simple protein precipitation extraction by acetonitrile, the analyte and IS were extracted from $50 \mu \mathrm{L}$ plasma sample on an Agilent Poroshell 120, EC-C18 $(50 \mathrm{~mm} \times 4.6$ mm, i.d., $2.7 \mu \mathrm{m})$ column using $5 \mu \mathrm{L}$ injection volume with a total run time of 2 min. Acidified methanol/water mixture was used as a mobile phase. The parent/product ion transitions for metolazone ( $\mathrm{m} / \mathrm{z}$ 366.1/258.9) and $I S(\mathrm{~m} / \mathrm{z}$ 429.2/207.0) were monitored on a triple quadrupole mass spectrometer, operating in the multiple reaction monitoring and positive ion mode. The method was found to be linear in the range of $0.05-200$ metolazone. The method was validated with respect to selectivity, linearity, accuracy, precision, recovery and stability according to accepted regulatory guidelines. The described method was successfully applied to preclinical pharmacokinetic studies of analytes after an oral administration of metolazone $(1 \mathrm{mg} / \mathrm{kg})$ in rats.
\end{abstract}

Keywords: LC-MS/MS; pharmacokinetic; metolazone; validated; rat plasma 


\section{INTRODUCTION}

Metolazone (MET), chemically known as (7-chloro- 2-methyl-3-(2-methylphenyl)-4oxo-2,3-dihydro-1Hquinazoline- 6-sulfonamide is a quinazoline diuretic, It acts primarily to inhibit sodium reabsorption at the cortical diluting site and to a lesser extent in the proximal convoluted tubule $[1,2]$.

Different analytical methods are reported in literature for the determination of MET individually and combination with other drugs in biological matrix including HPLC [3 - 7] LC-MS/MS [8 - 11] and UPLC-MS/MS [12, 13].

LC-MS/MS and UPLC-MS/MS were demonstrated to be superior to all the mentioned techniques in the literature for simultaneous quantification of drugs in biological matrix because its selectivity, sensitivity, simplicity and high-throughput [14]. Quantification of antihypertensive drugs in biological matrix is very important and necessary because majority of these drugs prescribed in combination to get better result and control blood pressure at the adequate level.

Hence, the main objective of this work was to developed and validated a simple, sensitive and high-throughput LC-MS/MS method for simultaneous quantification of MET in rat plasma and applied it in preclinical pharmacokinetic studies.

\section{EXPERIMENTAL}

\section{Chemicals and reagents}

MET (purity > $99.70 \%$ ) and Irbesartan (IS) ((purity > $99.90 \%$ ) were obtained from Aristo Pharmaceuticals Pvt. Ltd. (Mandideep, India). The chemical structures of MET, and IS are shown in Fig. 1. HPLC grade methanol, formic acid and orthophosphoric acid (85\%) were purchased from Merck Ltd. (Mumbai, India). Ultra-pure water $(18.2 \mathrm{M} \Omega \mathrm{cm}$ ) was obtained from a Milli-Q water purification system (Millipore, Milford, MA, USA). The HPLC mobile phase and sample aliquots were filtered through a $0.22 \mu \mathrm{m}$ Nylon- 66 filters (Aligent Technologies, USA) before use. Oasis ${ }^{\circledR}$ HLB $30 \mathrm{mg} / 1 \mathrm{cc}$ solid phase extraction cartridges were obtained from Waters (Minford, Massachusetts, USA).

\section{LC-MS/MS instrumentation}

The LC system consisted of an Agilent 1260 infinity HPLC system (Agilent Technologies, USA), which is equipped with a quaternary pump (G1311B), degasser (G1322A), Autosampler (G1329B) and a thermostated column compartment (G1316A). Chromatographic separation was carried on an Agilent Poroshell 120, EC- C18 (50 mm × 4.6 $\mathrm{mm}$, i.d., $2.7 \mu \mathrm{m}$ ) column at ambient temperature. An isocratic mobile phase consisting of 0.1 $\%$ formic acid in methanol and that in water $(80: 20, \mathrm{v} / \mathrm{v})$ with a flow rate of $0.5 \mathrm{~mL} / \mathrm{min}$ was used to seperate the analyte and IS up to a total retention time of $2 \mathrm{~min}$.

Mass spectrometric detection was performed using Agilent 6460 Triple Quadrupole mass spectrometer (Agilent Technologies, USA) was operated with Agilent G1948B electro spray ionization (ESI) source. The MS recordings were performed in the positive ion multiple reaction monitoring $(\mathrm{MRM})$ with drying gas temperature $\left(\mathrm{N}_{2}\right), 300^{\circ} \mathrm{C}$; gas flow, $8 \mathrm{~L} / \mathrm{min}\left(\mathrm{N}_{2}\right)$; nebulizer pressure, $45 \mathrm{psi}$; capillary voltage, $4000 \mathrm{~V}$. The optimized fragmentor voltage was set at 20 and $20 \mathrm{~V}$ for MET, and IS, respectively. The collision energy was set at 5 and $15 \mathrm{~V}$ for MET and IS, respectively. The precursor/product ion pairs monitored were $\mathrm{m} / \mathrm{z}$ $366.1 \rightarrow 258.9$, and $m / z$ 429.2 $\rightarrow 207.0$ for MET and IS, respectively. An Agilent MassHunter Workstation Software ((Agilent Technologies, USA) was used for all data acquisition, 


\section{Preparation of standards and quality control samples}

The stock solutions of MET and IS were prepared by dissolving appropriate amount corresponding to $1.0 \mathrm{mg} / \mathrm{mL}$ concentration of working standards in acetonitrile. The stock solutions were then serially diluted with a mobile phase consisting of acetonitrile of $0.1 \%$ formic acid in methanol and that in water $(80: 20, v / v)$ to provide working standard solutions at the desired concentrations. A $100 \mathrm{ng} / \mathrm{mL}$ IS working solution was prepared by diluting its stock solution with mobile phase.

The calibration standards for MET were prepared daily by spiking $20 \mu \mathrm{L}$ of the appropriate standard working solution of MET to $100 \mu \mathrm{L}$ blank wistrar rat plasma to provide the final concentrations of $0.05-250 \mathrm{ng} / \mathrm{mL}$. The quality control samples (QCs) for MET were prepared with $100 \mu \mathrm{L}$ blank plasma at LLOQ, low (LQC), middle (MQC) and high concentrations (HQC) of 0.05, 0.15. 80 and $200 \mathrm{ng} / \mathrm{mL}$, respectively. All solutions described above were stored at $4-8{ }^{\circ} \mathrm{C}$.

\section{Sample preparation}

A simple and rapid sample preparation technique has been chosen. A $100 \mu \mathrm{L}$ aliquot of rat plasma was transferred to a $2 \mathrm{~mL}$ polypropylene micro test tube, and deproteinized by mixing it with $100 \mu \mathrm{l}$ of IS working solution containing $200 \mathrm{ng}$ of MET per $\mathrm{mL}$ of acetonitrile, vortex-mixed for $10 \mathrm{~s}$ and centrifuged for $10 \mathrm{~min}$ at $4000 \mathrm{rpm}$. A $5 \mu \mathrm{l}$ of the supernatant was directly injected in to LC-MS/MS for analysis.

\section{RESULTS AND DISCUSSION Optimization of method}

The main objective of our research work was to develop a simple, sensitive and high throughput LC-MS/ MS method, which is having a simple extraction procedure from small volumes of plasma, high recoveries and a short run time. To get the richest relative abundance of precursor ions and product ions, the parameters for fragmentor energies and collision energies were optimized, and the MRM transitions in positive ion mode were chosen to be for $\mathrm{m} / \mathrm{z} \quad 366.1 \rightarrow 258.9$, and $\mathrm{m} / \mathrm{z} \quad 429.2 \rightarrow 207.0$ for MET and IS, respectively. The product ion mass spectra of the analyte and IS are shown in Fig. 1.

The feasibility of several mixture of solvent such as acetonitrile using different buffers such as formic acid, ammonium acetate and ammonium formate, were investigated and compared to identify the optimal mobile phase. Finally, MET and IS was eluted up to a total retention time of $1.5 \mathrm{~min}$ using an isocratic mobile phase consisting of $0.1 \%$ formic acid in methanol and that in water $(80: 20, \mathrm{v} / \mathrm{v})$ with a flow rate of $0.5 \mathrm{~mL} / \mathrm{min}$, and the injection volume was $5 \mu \mathrm{L}$.

Several organic solvents (methanol, acetonitrile, water or mixture of these solvents) were tried for the preparation of stock solutions of MET. Acetonitrile was selected due to greater solubility and stability of analyte and IS in it. Various organic solvents including methanol, acetonitrile, acetone, ethanol or a mixture of these solvent at various proportions were investigated for the extraction of MET and IS from plasma samples. Acetonitrile provided the best recoveries with minimum endogenous interferences and was chosen as the extraction solvent. 

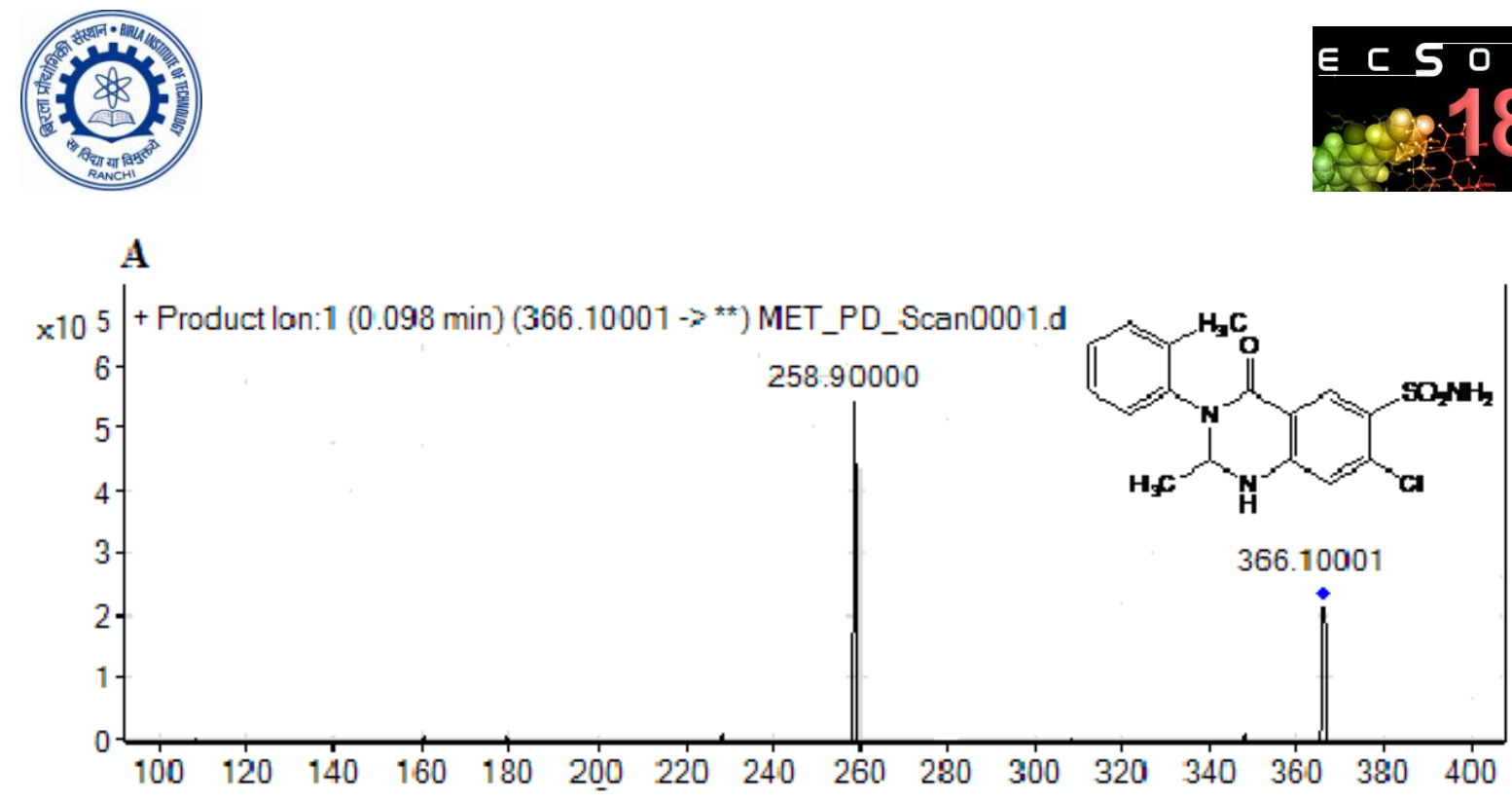

B

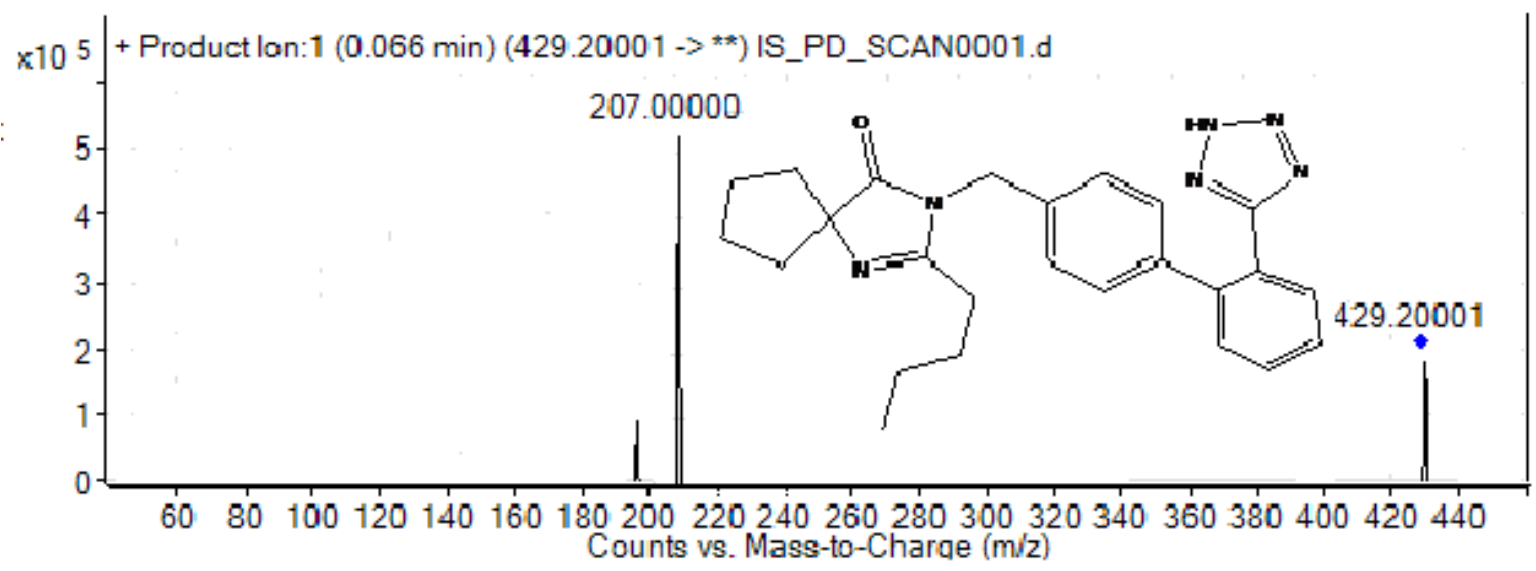

Fig. 1 Chemical structure and product ion mass spectra of [Metolazone (MET), (A)] and [Irbesartan (IS), (B)].

\section{Method Validation}

The developed method was validated for selectivity, linearity, accuracy and intra-day and inter-day precision, recovery, matrix effect and stability according to the Food and Drug Administration (FDA) guidelines for bioanalytical method validation and other related guidelines [15].

\section{Selectivity}

The developed LC-MS/MS method demonstrated good selectivity as the extracted ion chromatograms showed there were no interferences at the same retention time of MET $(0.73$ $\mathrm{min}$ ) and IS ( $1.54 \mathrm{~min}$ ). Representative chromatograms of blank plasma, blank plasma spiked ith MET at LLOQ level and IS at $100 \mathrm{ng} / \mathrm{mL}$ and extracted plasma samples are shown in Fig. 2. These results supported the high specificity and selectivity of this method. 
+ MRM (366.1 $>258.9)$ Blank_00.d

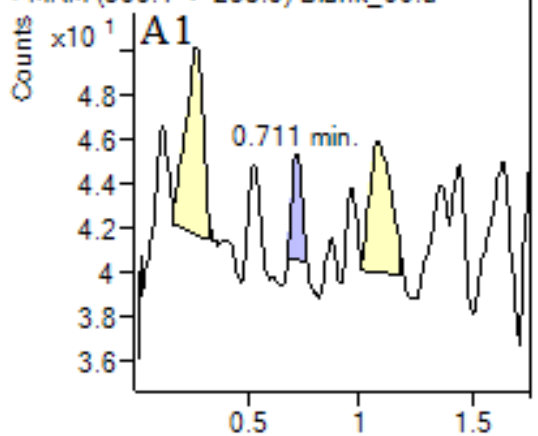

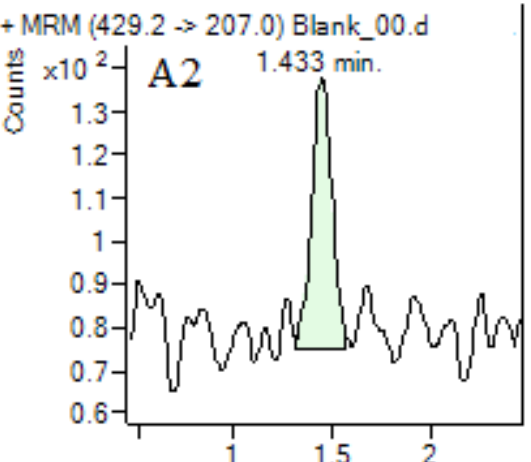

+ MRM $(429.2 \rightarrow 207.0)$
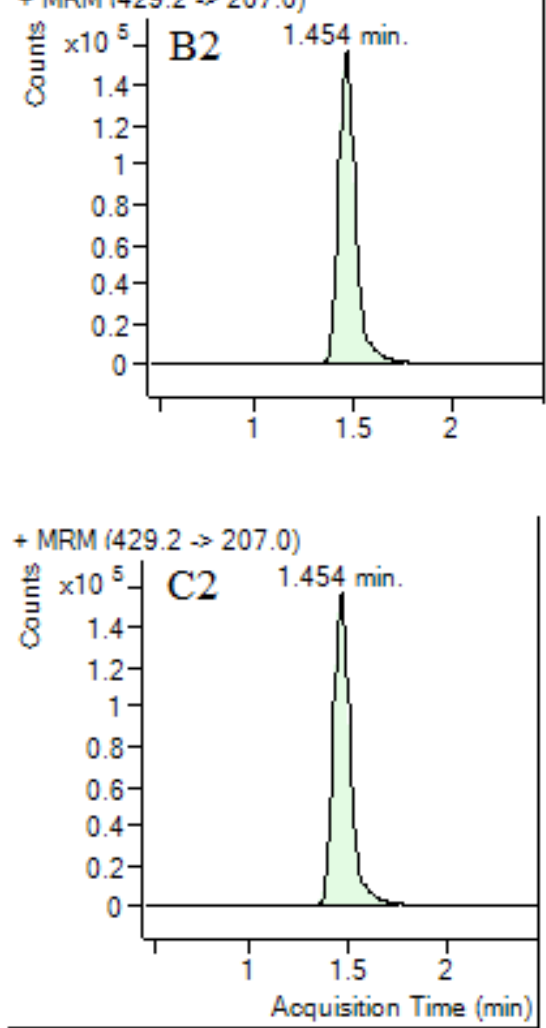

Fig. 2 Representative MRM chromatogram of blank plasma samples: MET (A1) and IS (A2). Representative MRM chromatogram of a plasma sample of MET at LLOQ level (B1) and IS at $100 \mathrm{ng} / \mathrm{mL}$ (B2). Representative MRM chromatogram of a plasma sample of MET (C1) obtained from a rat at $3 \mathrm{~h}$ after an oral administration of MET and IS at $100 \mathrm{ng} / \mathrm{mL}$ (C2).

\section{Extraction recovery and matrix effects}

The extraction recoveries $(\mathrm{n}=6)$ of MET from rat plasma at concentration levels of , $0.05,0.15 .80$ and $200 \mathrm{ng} / \mathrm{mL}$ were $>85 \%$ respectively. The mean extraction recovery $(\mathrm{n}=$ 6) of IS was $87.20 \pm 6.20 \%$.. The matrix effects values were all observed between 97 and $101.50 \%$, which means either ionization suppression or enhancement from the plasma matrix was negligible for this method [Table I] 


\begin{tabular}{|c|c|c|c|c|c|}
\hline \multirow[t]{2}{*}{ Analytes } & \multirow{2}{*}{$\begin{array}{l}\text { Nominal conc. } \\
(\mathrm{ng} / \mathrm{mL})\end{array}$} & \multicolumn{2}{|c|}{ Recovery (\%) } & \multicolumn{2}{|c|}{ Matrix effect (\%) } \\
\hline & & Mean \pm SD & \%RSD & Mean \pm SD & $\operatorname{RSD}(\%)$ \\
\hline \multirow{4}{*}{ MET } & 0.05 & 75.25 & 9.80 & 90.20 & 10.20 \\
\hline & 0.5 & 78.60 & 6.95 & 93.50 & 6.68 \\
\hline & 80 & 80.26 & 4.60 & 90.95 & 5.50 \\
\hline & 200 & 80.53 & 3.10 & 89.85 & 3.85 \\
\hline IS & 200 & 93.60 & 3.15 & 92.90 & 3.06 \\
\hline
\end{tabular}

\section{Sensitivity and linearity}

The linearity of each calibration curve was determined by plotting the peak-area ratio $(Y)$ of MET to IS (MET/IS) versus the nominal concentration $(X)$ of MET. The calibration curves were obtained by weighted $(1 / X)$ linear regression analysis. To evaluate the linearity calibration curves were determined in triplicate $(n=6)$ on three separate days. The representative regression equation for the calibration curve was found to be linear with a correlation coefficient of 0.999 . The lower limit of quantitation (LLOQ) of the assay was $0.15 \mathrm{ng} / \mathrm{mL}$ for MET with accuracy less than $\pm 10 \%$ and a precision less than $9 \%$.

\section{Precision and accuracy}

The precision and accuracy of the developed method were determined by analysis three levels of quality control (at LQC, MQC and HQC) samples. Intra-batch and inter batch precision precision were found to be less than $10 \%$ for MET. Accuracy was expressed as percent relative error (\%RE) and found to be within limits from the nominal concentration. The result intra- and inter-day precisions and accuracies of MET were summarized in Table II.

Table II. Intra- and inter-day precision and accuracy in determination of MET, LOS and LCA in rat plasma

\begin{tabular}{lcccc}
\hline \multicolumn{1}{c}{ Analytes } & $\begin{array}{c}\text { Nominal Conc. } \\
(\mathbf{n g} / \mathbf{m L})\end{array}$ & $\begin{array}{c}\text { Mean Conc. found } \\
(\mathbf{n g} / \mathbf{m L}) \pm \mathbf{S D}\end{array}$ & $\begin{array}{c}\text { Accuracy }^{*} \\
(\boldsymbol{\%})\end{array}$ & Precision $^{\#}(\%)$ \\
\hline MET & & & & \\
Intra-day (n=6) & 0.05 & $0.05 \pm 0.01$ & 104.00 & 7.90 \\
& 0.5 & $0.52 \pm 0.20$ & 104.36 & 3.87 \\
& 80 & $79.95 \pm 1.16$ & 99.93 & 1.46 \\
Inter-day (n=6) & 200 & $201.25 \pm 2.09$ & 100.60 & 1.04 \\
& 0.05 & $0.05 \pm 0.01$ & 106.00 & 8.20 \\
& 0.5 & $0.508 \pm 0.30$ & 101.60 & 3.20 \\
& 80 & $80.85 \pm 1.85$ & 99.93 & 1.46 \\
\hline
\end{tabular}

*Expressed as [(mean observed concentrations/nominal concentrations $) \times 100]$

"Expressed as relative standard deviation (RSD)

\section{Stability studies}

The stability studies of MET and IS were performed at three QC concentrations (LQC, MQC and LQC) levels in six replicates $(n=6)$. The stability in rat plasma was evaluated under different temperature and storage conditions, such as: short-term stability at room temperature for $12 \mathrm{~h}$; long-term stability at $-80^{\circ} \mathrm{C}$ for 45 days; three freeze $\left(-20^{\circ} \mathrm{C}\right)$ thaw (room temperature) cycles on consecutive days. Post - preparation stability was 

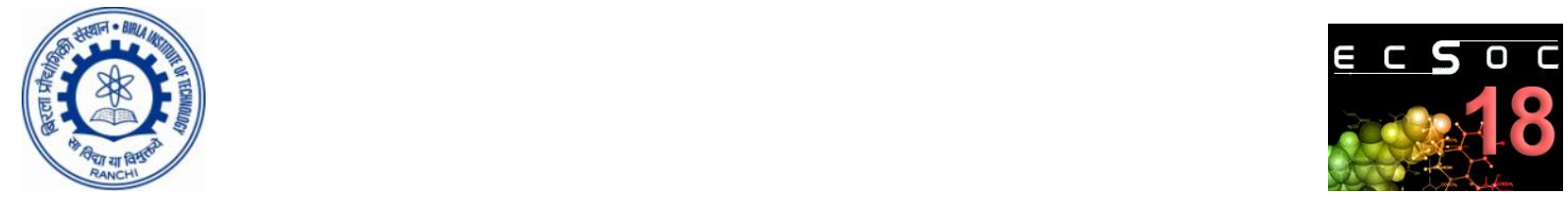

evaluated by keeping extracted QC samples in the autosampler at $4{ }^{\circ} \mathrm{C}$ for $24 \mathrm{~h}$. The stability of stock solutions ( $4-8^{\circ} \mathrm{C}$ for 7 days) of MET and IS was also evaluated. The results of stability studies are summarized in Table III.

\begin{tabular}{|c|c|c|c|c|c|c|c|c|c|c|c|}
\hline \multicolumn{12}{|c|}{ Table III. Stability of METIS after storage under indicated condition (mean \% \pm S.D., n=6) } \\
\hline \multirow[b]{2}{*}{ Analytes } & \multirow[b]{2}{*}{$\begin{array}{l}\text { Nominal } \\
\text { Conc. } \\
\text { ng/mL }\end{array}$} & \multicolumn{2}{|c|}{$\begin{array}{c}\text { Bench - top } \\
\text { stability at } 24 \\
{ }^{\circ} \mathrm{C}\end{array}$} & \multicolumn{2}{|c|}{$\begin{array}{l}\text { Long term } \\
\text { stability at - } \\
80^{\circ} \mathrm{C} \\
\text { (90 days) }\end{array}$} & \multicolumn{2}{|c|}{$\begin{array}{l}\text { Auto sampler } \\
\text { stability at } \\
24^{\circ} \mathrm{C}(24 \text { h })\end{array}$} & \multicolumn{2}{|c|}{$\begin{array}{c}\text { Freeze thaw } \\
\text { stability (from } \\
-80^{\circ} \mathrm{C} \text { to } 24^{\circ} \mathrm{C}\end{array}$} & \multicolumn{2}{|c|}{$\begin{array}{c}\text { Stock } \\
\text { solution } \\
\text { stability } \\
4 \text { - } 8^{\circ} \mathrm{C} \\
\text { (7 days) }\end{array}$} \\
\hline & & $\begin{array}{l}\text { Conc. } \\
\text { found } \\
\mathrm{ng} / \mathrm{mL} \\
\pm \mathrm{SD}\end{array}$ & $\begin{array}{l}\mathrm{CV} \\
(\%)\end{array}$ & $\begin{array}{l}\text { Con. } \\
\text { Found } \\
\mathrm{ng} / \mathrm{mL} \\
\pm \mathrm{SD}\end{array}$ & $\begin{array}{l}\mathrm{CV} \\
(\%)\end{array}$ & $\begin{array}{l}\text { Conc. } \\
\text { found } \\
\mathrm{ng} / \mathrm{mL} \\
\pm \mathrm{SD}\end{array}$ & $\begin{array}{l}\mathrm{CV} \\
(\%)\end{array}$ & $\begin{array}{l}\text { Conc.found } \\
\mathrm{ng} / \mathrm{mL} \\
\pm \mathrm{SD}\end{array}$ & $\begin{array}{l}\mathrm{CV} \\
(\%)\end{array}$ & $\begin{array}{l}\text { Conc. } \\
\text { found } \\
\mathrm{ng} / \mathrm{mL} \\
\pm \mathrm{SD}\end{array}$ & $\begin{array}{l}\mathrm{CV} \\
(\%)\end{array}$ \\
\hline \multirow[t]{3}{*}{ MET } & 0.5 & $\begin{array}{c}0.51 \\
\pm 0.20\end{array}$ & 3.87 & $\begin{array}{c}0.53 \\
\pm 0.10\end{array}$ & 3.55 & $\begin{array}{c}0.49 \\
\pm 0.15\end{array}$ & 3.90 & $\begin{array}{c}0.51 \\
\pm 0.25\end{array}$ & 3.81 & $\begin{array}{c}0.50 \\
\pm 0.15\end{array}$ & 1.89 \\
\hline & 80 & $\begin{array}{c}79.95 \\
\pm 1.16\end{array}$ & 1.46 & $\begin{array}{c}80.10 \\
\pm 1.16\end{array}$ & 1.46 & $\begin{array}{r}79.99 \\
\pm 1.15\end{array}$ & 1.40 & $\begin{array}{r}79.90 \\
\pm 1.50\end{array}$ & 1.55 & $\begin{array}{r}80.10 \\
\pm 1.15\end{array}$ & 1.50 \\
\hline & 200 & $\begin{array}{l}201.00 \\
\pm 2.09\end{array}$ & 1.04 & $\begin{array}{l}201.00 \\
\pm 1.19\end{array}$ & 1.03 & $\begin{array}{l}203.15 \\
\pm 2.15\end{array}$ & 1.09 & $\begin{array}{l}200.98 \\
\pm 2.18\end{array}$ & 1.01 & $\begin{array}{l}202.10 \\
\pm 1.48\end{array}$ & 1.60 \\
\hline IS & 200 & $\begin{array}{r}196.20 \\
\pm 5.10 \\
\end{array}$ & 2.89 & $\begin{array}{l}196.13 \\
\pm 2.17 \\
\end{array}$ & 4.85 & $\begin{array}{l}197.14 \\
\pm 3.12\end{array}$ & 2.54 & $\begin{array}{l}195.54 \\
\pm 1.89\end{array}$ & 3.33 & $\begin{array}{l}196.98 \\
\pm 1.87\end{array}$ & 2.10 \\
\hline
\end{tabular}

\section{Application to pharmacokinetic study}

All animal studies described were approved by the institutional animal ethical committee prior to the study. Six young and healthy male wistrar rats weighing $250 \pm 50 \mathrm{~g}$ were obtained from the Laboratory Animal Center, Department of Pharmaceutical Science and Technology, Mesra, Ranchi and housed in an environmentally controlled room (temperature: $20 \pm 2{ }^{\circ} \mathrm{C}$, humidity: $60 \pm 5{ }^{\circ} \mathrm{C}, 12 \mathrm{~h}$ dark/light cycle) for at least seven days before the experiment. The rodents were given a commercial rat chow and water ad libitum. Before oral administration of the MET at $1 \mathrm{mg} / \mathrm{Kg}$, it is dissolved in $0.1 \%$ carboxy methyl cellulose, the rats were fasted for $12 \mathrm{~h}$, but allowed free access to water. Approximately 250 $\mu \mathrm{L}$ blood samples were collected into heparinized tubes via ocular puncture before drug administration and at $0.15 \mathrm{~h}, 0.25 \mathrm{~h}, 0.5 \mathrm{~h}, 1 \mathrm{~h}, 1.5 \mathrm{~h}, 2 \mathrm{~h}, 3 \mathrm{~h}, 4 \mathrm{~h}, 6 \mathrm{~h}, 8 \mathrm{~h}, 12 \mathrm{~h}, 24 \mathrm{~h}, 36 \mathrm{~h}$ and $48 \mathrm{~h}$ using spares sampling after drug administration, and centrifuged at $6000 \mathrm{rpm}$ for $10 \mathrm{~min}$ to separate out plasma. These plasma samples were stored at $-80{ }^{\circ} \mathrm{C}$ immediately prior to analysis.

Pharmacokinetic (PK) analysis was performed using the software Phoenix ${ }^{\circledR}$ WinNonlin ${ }^{\circledR}$ (version 6.3; Certara USA, Inc., St. Louis, USA) on the rat plasma data of MET using non-compartmental methods. The present method was applied successfully to the pharmacokinetic study of MET in six male wistrar rats after an oral administration of MET (1 $\mathrm{mg} / \mathrm{kg}$ ). A representative chromatogram of post - dose sample (after $1.0 \mathrm{~h}$ ) is shown in Fig. 2. The resulting mean plasma concentration - time curve of MET is shown in Fig. 3 and main pharmacokinetic parameters are summarized in Table IV. 


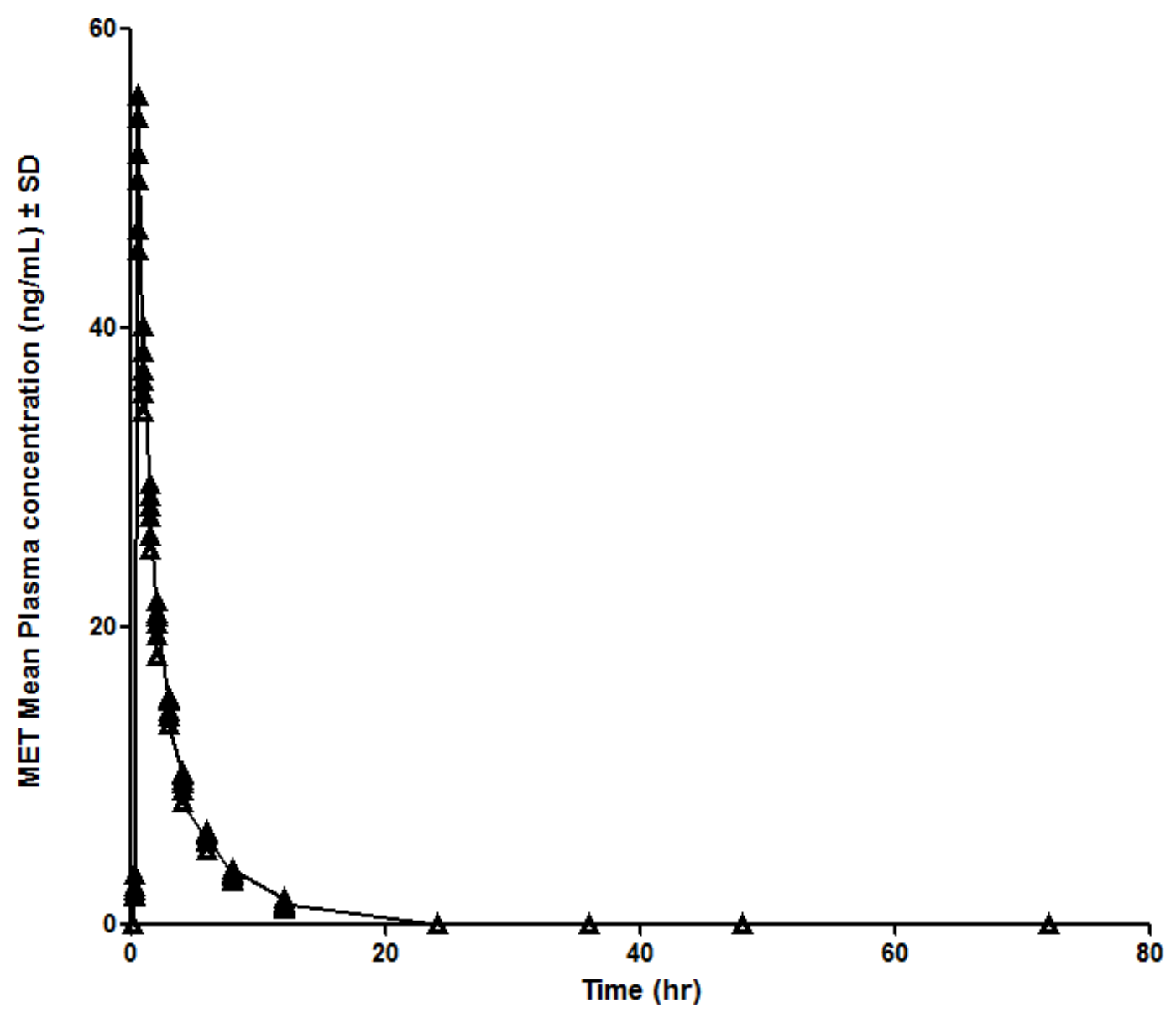

Fig. 3 Mean plasma concentration Vs time curve of MET.

Table: IV. Pharmacokinetic parameters obtained after oral administration of $1 \mathrm{mg} / \mathrm{kg}$ MET

\begin{tabular}{ll}
\hline AUC $(0-48 \mathrm{~h})(\mathrm{hr} \times \mathrm{ng} / \mathrm{mL})$ & 638.31 \\
AUCinf $(\mathrm{hr} \times \mathrm{ng} / \mathrm{mL})$ & 655.20 \\
Cmax $(\mathrm{ng} / \mathrm{mL})$ & 58.77 \\
Kel $(1 / \mathrm{hr})$ & 0.07 \\
MRT $(0-48 \mathrm{~h})(\mathrm{hr})$ & 11.16 \\
T1/2(z) $(\mathrm{hr})$ & 9.39 \\
Tmax $(\mathrm{hr})$ & 3.00 \\
SE_AUC $(0-48 \mathrm{~h})(\mathrm{hr} \times \mathrm{ng} / \mathrm{mL})$ & 9.48 \\
SE_Cmax $(\mathrm{ng} / \mathrm{mL})$ & 0.38 \\
\hline
\end{tabular}

\section{CONCLUSION}

In summary, for the first time a simple, sensitive and selective LC-MS/MS method using a simple protein precipitation sample preparation procedure has been developed and validated for the determination of MET in rat plasma. This LC-MS/MS method was successfully applied to pharmacokinetic studies after an oral administration of MET (1 mg $/ \mathrm{kg}$ ) in rats. The advantages of the developed method include simple sample preparation procedures, short analysis time ( 2 min per sample), and high sensitivity (LLOQ at 0.05 
$\mathrm{ng} / \mathrm{mL}$ ) which rendered the method fits for the purpose of its application to measure concentration-time profiles for bioavailability, pharmacokinetic, bioequivalence and drug drug interaction studies of MET for routine therapeutic drug monitoring.

\section{REFERENCES}

[1] K. S. Channer, K. A. McLean, P. Lawson-Matthew and M. Richardson. Combination diuretic treatment in severe heart failure: A randomised controlled trial. Br. Heart. J. 71: 146-150 (1994).

[2] D. A. Sica and T. W. Gehr. Clin. Pharmacokinet. Diuretic combinations in refractory oedema states: Pharmacokinetic-pharmacodynamic relationships. 30: 229-249 (1996).

[3] R. R. Brodie, L. F. Chasseaud and L. M. Walmsley. Determination of diuretic agent metolazone in by high- performance liquid chromatography. J. Chromatogr. B 226: 526-532 (1981).

[4] D. Farthing, I. Fakhry, T. W. Gehr, D. A. Sica. Novel high-performance liquid chromatographic method using solid-phase on-line elution for determination of metolazone in plasma and whole blood. J. Chromatogr. B 534: 228-232 (1994).

[5] B. Basvan, M. Selvadurai, N. M. Subramaniya and S. Bhojraj. Pharmacokinetic evaluation of metolazone tablets using healthy human volunteers. J Bioequiv Availab 2: 015-017 (2010).

[6] M. I. Walash, N. El-Enany, M. I. Eid and M. E. Fathy. Simultaneous determination of metolazone and spironolactone in raw materials, combined tablets and human urine by high performance liquid chromatography. Anal. Methods. 5: 5644-5656 (2013.)

[7] W. Guangli, X. Shuhua and L. Changxiao. Determination of metolazone in human blood by liquid chromatography with electrospray ionization tandem mass spectrometry. $J$. Chromatogr. B. 845: 169-173 (2007).

[8] S. M. N. Roy, K. V. Mangaonkar, S. M. Yetal and S. S. Joshi. LC-MS-MS Method for Determination of Metolazone in Human Plasma. J. Chem. 5: 634-640 (2008).

[9] J. Y. Jia, M. Q. Zhang, Y. M. Liu, Y. Liu, G. Y. Liu, S. J. Li, C. Lu, L. P. Weng, Y. Qi and C. Yu. Pharmacokinetics and Bioequivalence Evaluation of Two Losartan Potassium 50mg Tablets: A Single-Dose, Randomized-Sequence, Open-Label, Two-Way Crossover Study in Healthy Chinese Male Volunteers. Clin. Ther. 32: 1387-1395 (2010).

[10] Y. Chen and K. Hsu. Development of a LC-MS/MS-based method for determining metolazone concentrations in human plasma: Application to a pharmacokinetic study. $J$. Food Drug Anal. 21: 154-159 (2013).

[11] G. J. Murray and J. P. Danaceau. Simultaneous extraction and screening of diuretics, beta-blockers, selected stimulants and steroids in human urine by HPLC-MS/MS and UPLCMS/MS. J. Chromatogr. B. 877: 3857-3864 (2009).

[12] A. J. Girona, K. Deventer, K. Roels and P. V. Eenoob. Development and validation of an open screening method for diuretics, stimulants and selected compounds in human urine by UHPLC-HRMS for doping control Anal. Chim. Acta. 721: 137-146 (2012).

[13] D. Farthing, D. A. Sica, I. Fakhry and T.W.B. Gehr. Novel high-performance liquid chromatographic method using solid-phase on-line elution for determination of metolazone in plasma and whole blood. J. Chromatogr. B. 653:171-176 (1994).

[14] J. S. Kang (2012). Principles and Applications of LC-MS/MS for the Quantitative Bioanalysis of Analytes in Various Biological Samples, Tandem Mass Spectrometry Applications and Principles, Dr Jeevan Prasain (Ed.), ISBN: 978-953-51-0141-3, InTech.

[15] Guidance for Industry: Bioanalytical Method Validation; U.S. Department of Health and Human Services, Food and Drug Administration, Center for Drug Evaluation and Research (CDER), Center for Veterinary Medicine (CVM), BP (2001). 